\title{
Nanotechnology in Biomedical Applications
}

Jessica Koehne and M. Meyyappan

NASA Ames Research Center

Moffett Field, CA 94035

m.meyyappan@nasa.gov

Acknowledgement: Hua Chen, Prabhu Arumugam, Jun Li, Russell Andrews, Jing Li, Y. Lu, David Loftus, Pho Nguyen 


\section{Outline}

- Carbon Nanofiber (CNF) Nanoelectrode Array for Biosensors

- CNF Nanoelectrode Array for Deep Brain Stimulation

- Gas/Vapor Sensors for Medical Diagnosis

- CNT in Ophthalmological Applications 


\section{Nanoelectrode Array for Biosensors}

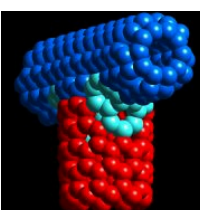

NACNT

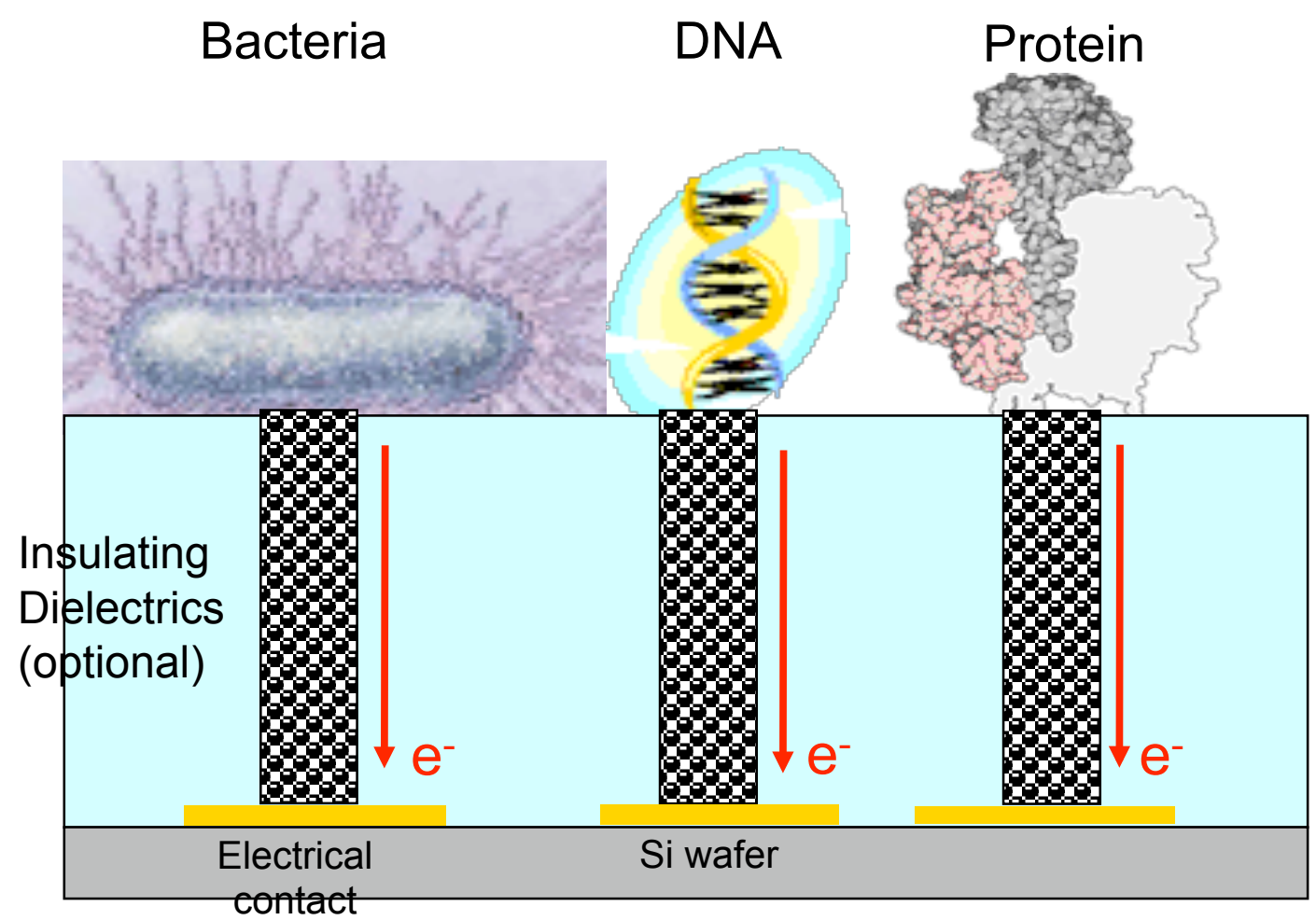

Directly interface solid-state electronics with DNAs, RNAs, proteins, and microbes in a miniaturized multiplex chip for quick detection (Lock and Key approach) 


\section{Nanoelectrode for Sensors}

Nanoscale electrodes create a dramatic improvement in signal detection over traditional electrodes

Traditional Macro- or

Electrode

Micro- Electrode

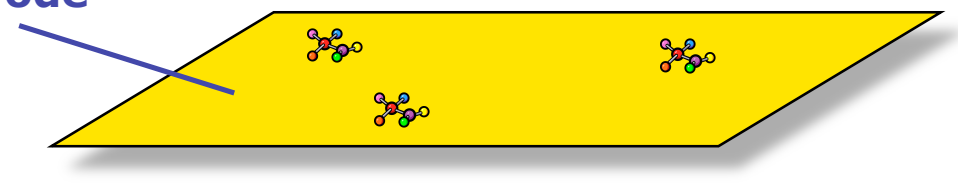

- Scale difference between macro-/ micro- electrodes and molecules is tremendous

- Background noise on electrode surface is therefore significant

- Significant amount of target molecules required

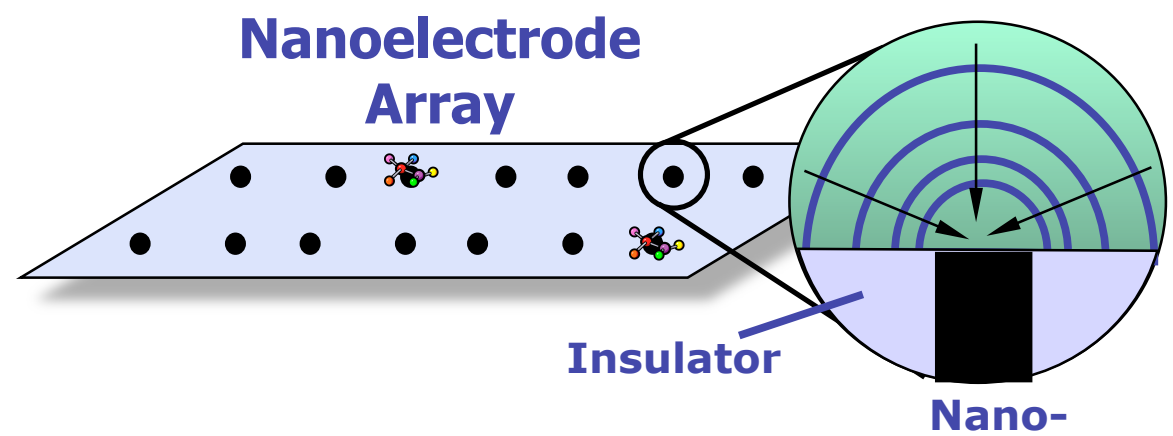

- CNT tips are at the scale close Electrode to molecules

- Dramatically reduced background noise

- Multiple electrodes result in magnified signal and desired redundance for statistical reliability.

Candidates: SWTTs, MWNTs, Vertical

CNFs or Vertical SiNWs 


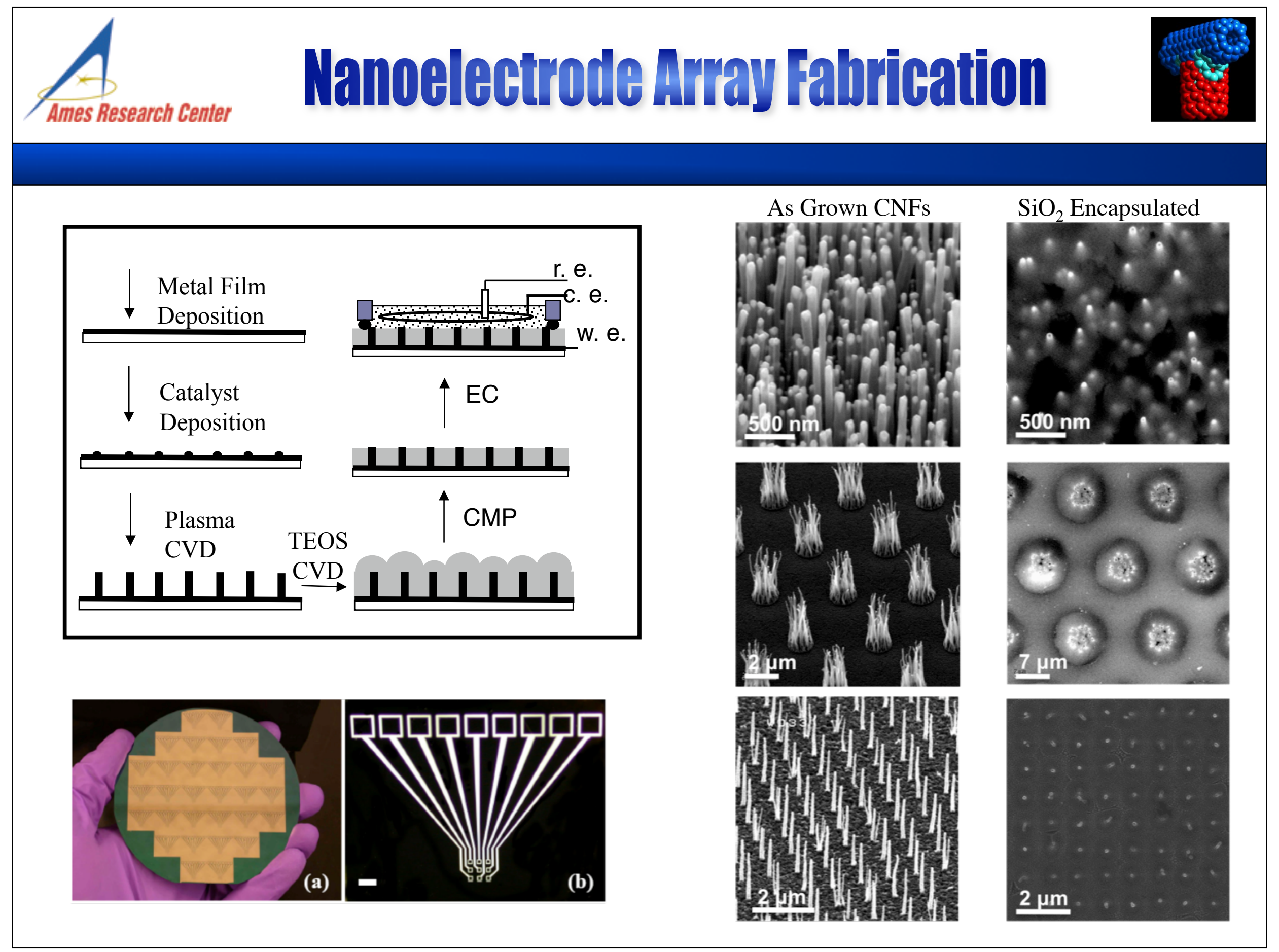




\section{GNF Growth by}

\section{Plasma Enhanced Chemical Vapor Deposition [PECVID]}

PECVD Reactor Schematic

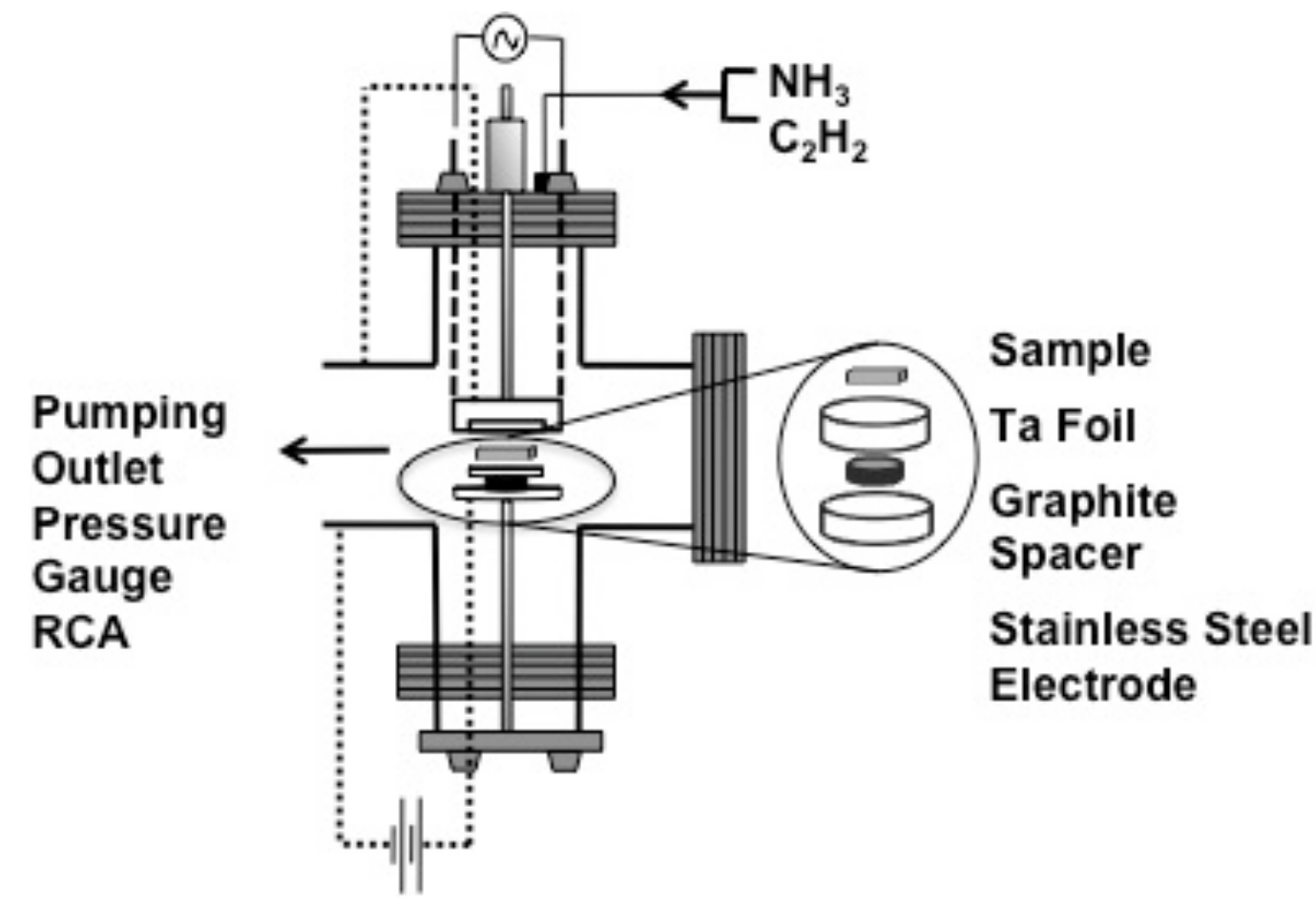

Custom Built PECVD Reactor

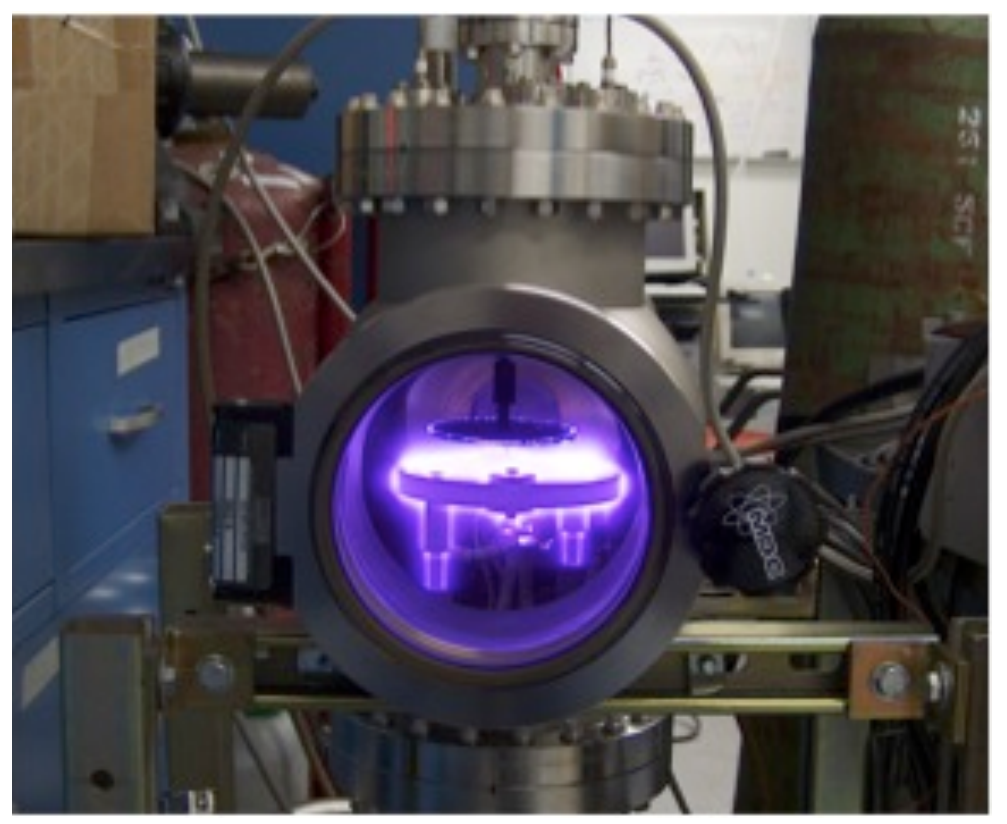

Growth Process

- Heated to $650 \mathrm{C}$

- Plasma discharge $500 \mathrm{~W}, 530 \mathrm{~V}, 0.97 \mathrm{~A}$

- $150 \mathrm{sccm} \mathrm{NH} / 50 \mathrm{sccm} \mathrm{C}_{2} \mathrm{H}_{2}$, 5-6 torr

- Growth rate- $1000 \mathrm{~nm} / \mathrm{min}$

- Quality is good, alignment is good 
- Probe molecule that would serve as signature for specific cancer cells to be attached to CNF ends

- Current flow upon hybridization through CNF electrode to signal processing IC chip.

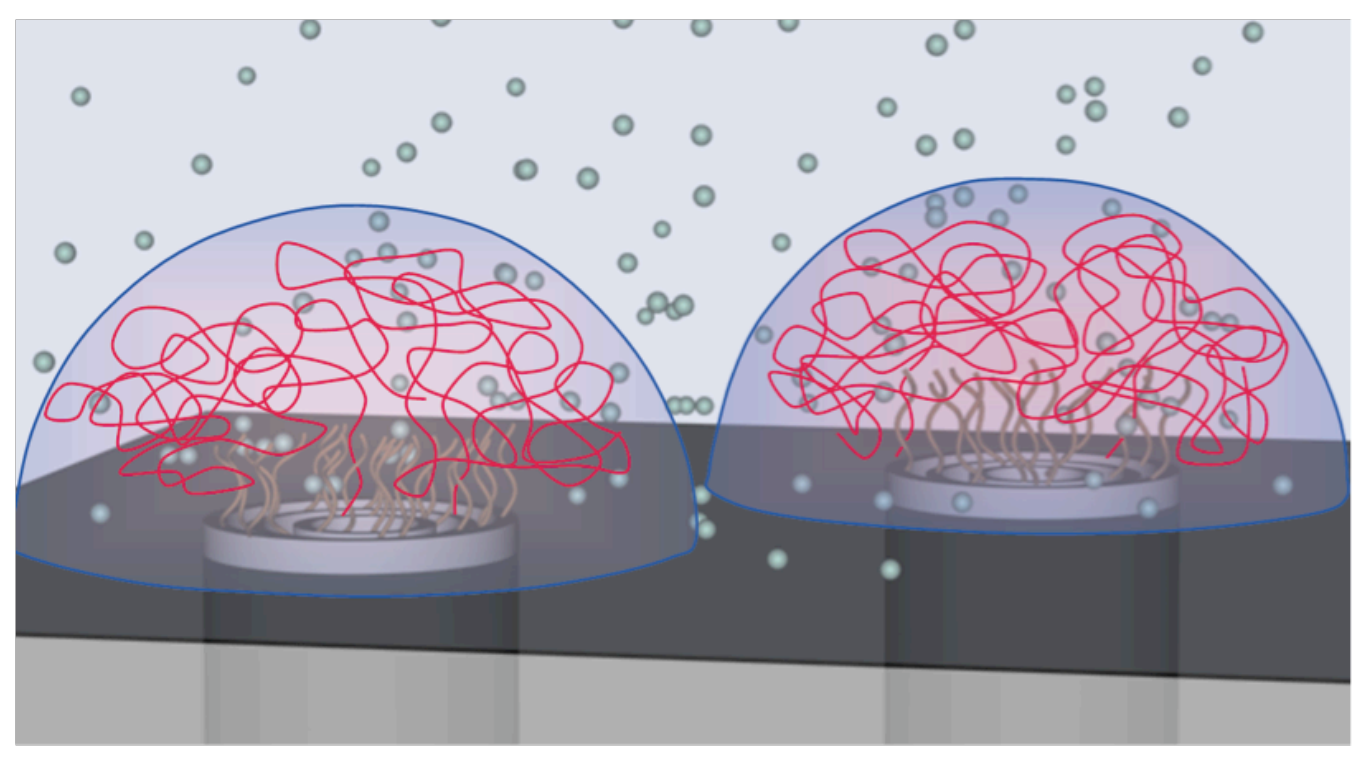

CNF-based

biosensor for cancer diagnostics

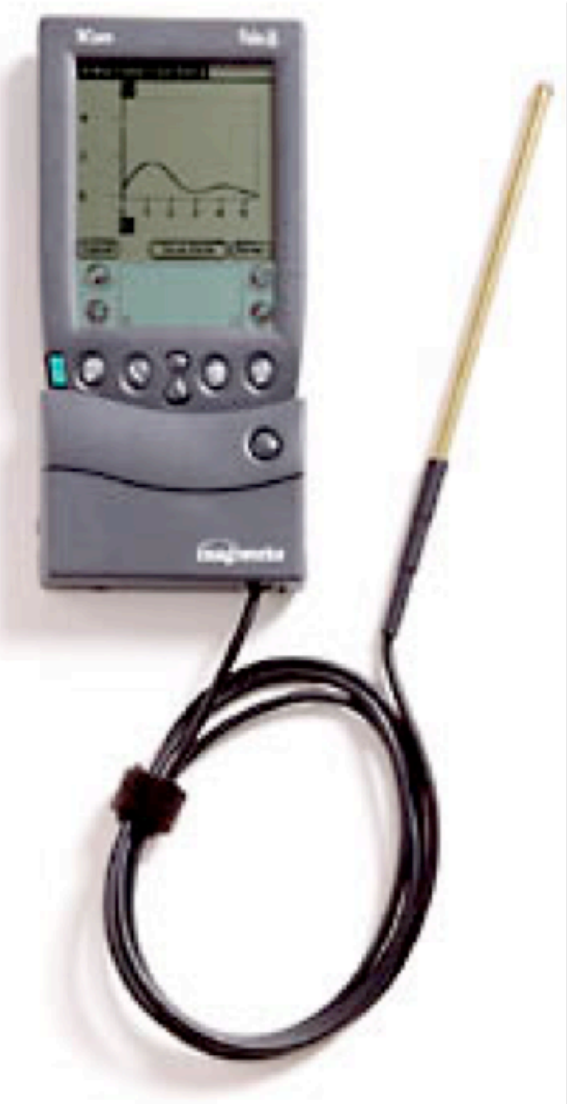


Electrochemically produce carboxylic acid groups on the surface in $1 \mathrm{M} \mathrm{NaOH}(1.5 \mathrm{~V} 60 \mathrm{sec}$ etch)

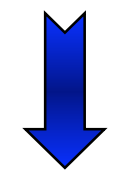

Highly selective reaction of primary amine with surface carboxylic acid group

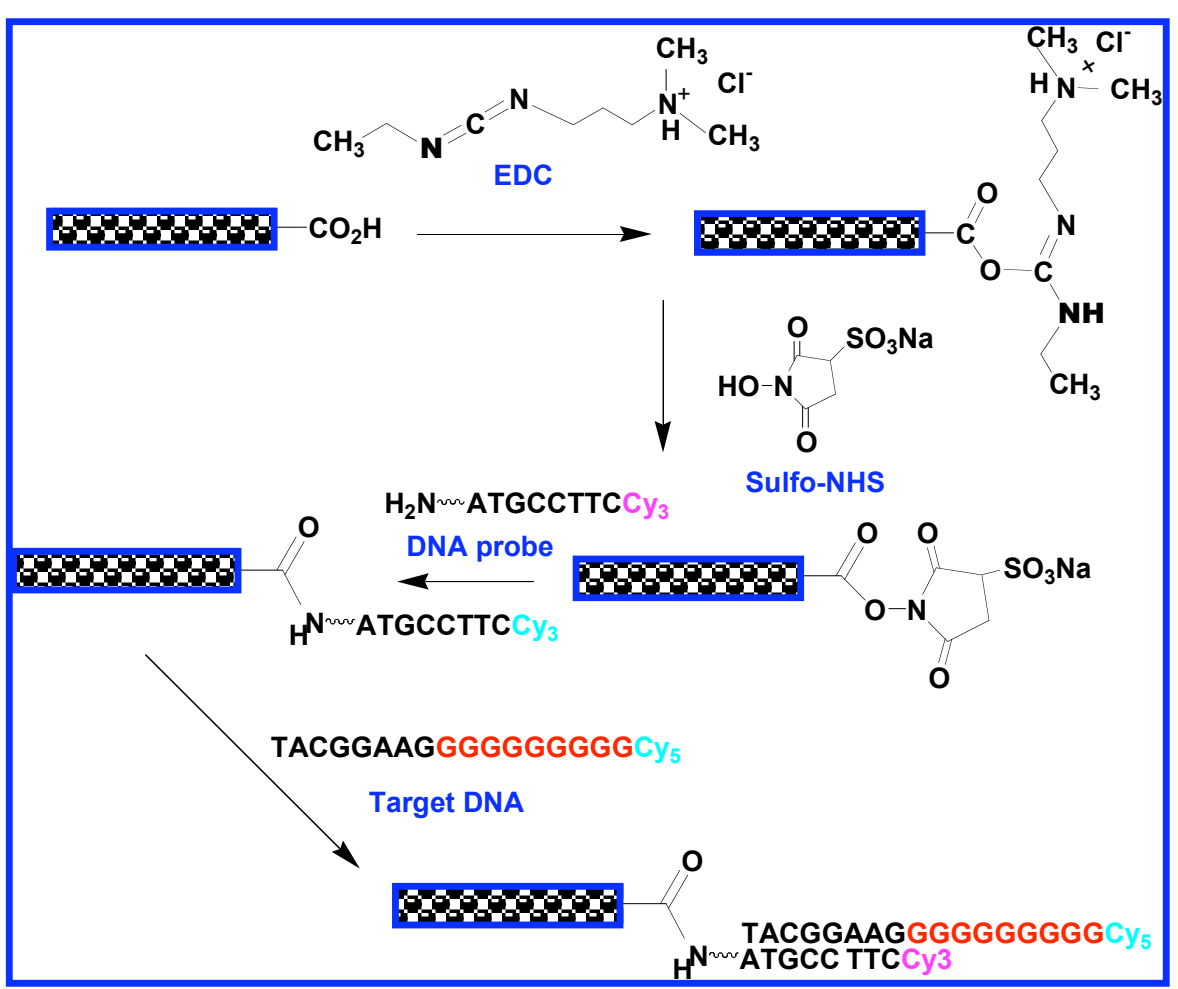
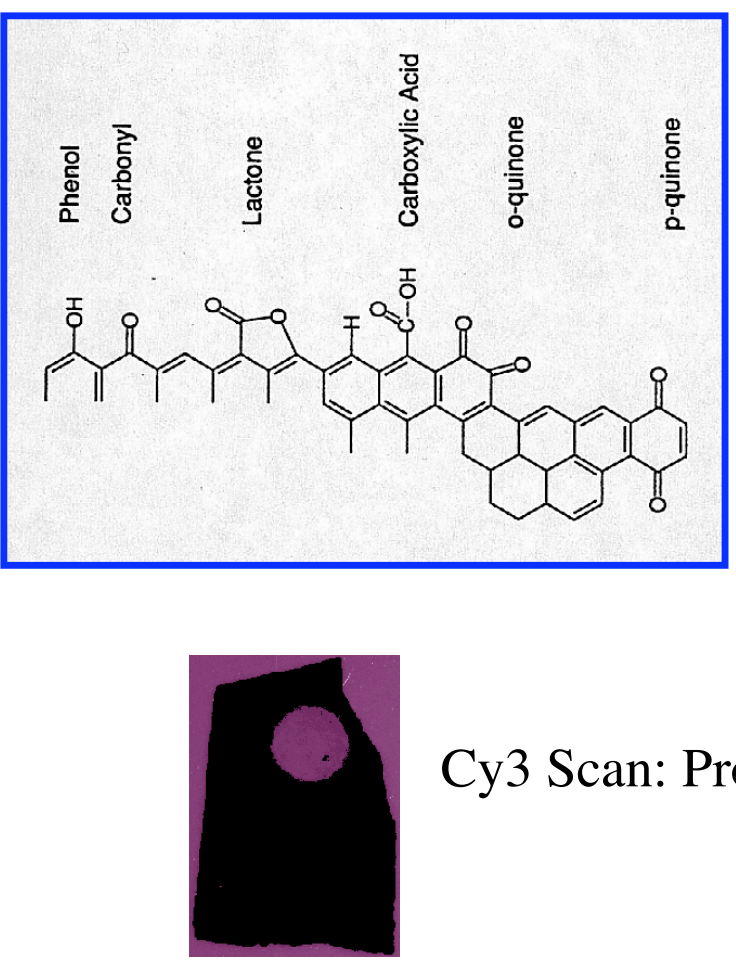

Cy3 Scan: Probe DNA

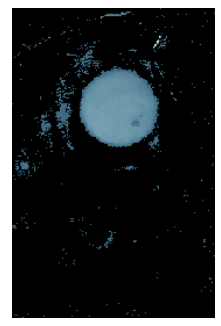

Cy5 Scan: Target DNA 


\section{llectrochemical Detection Methodology}

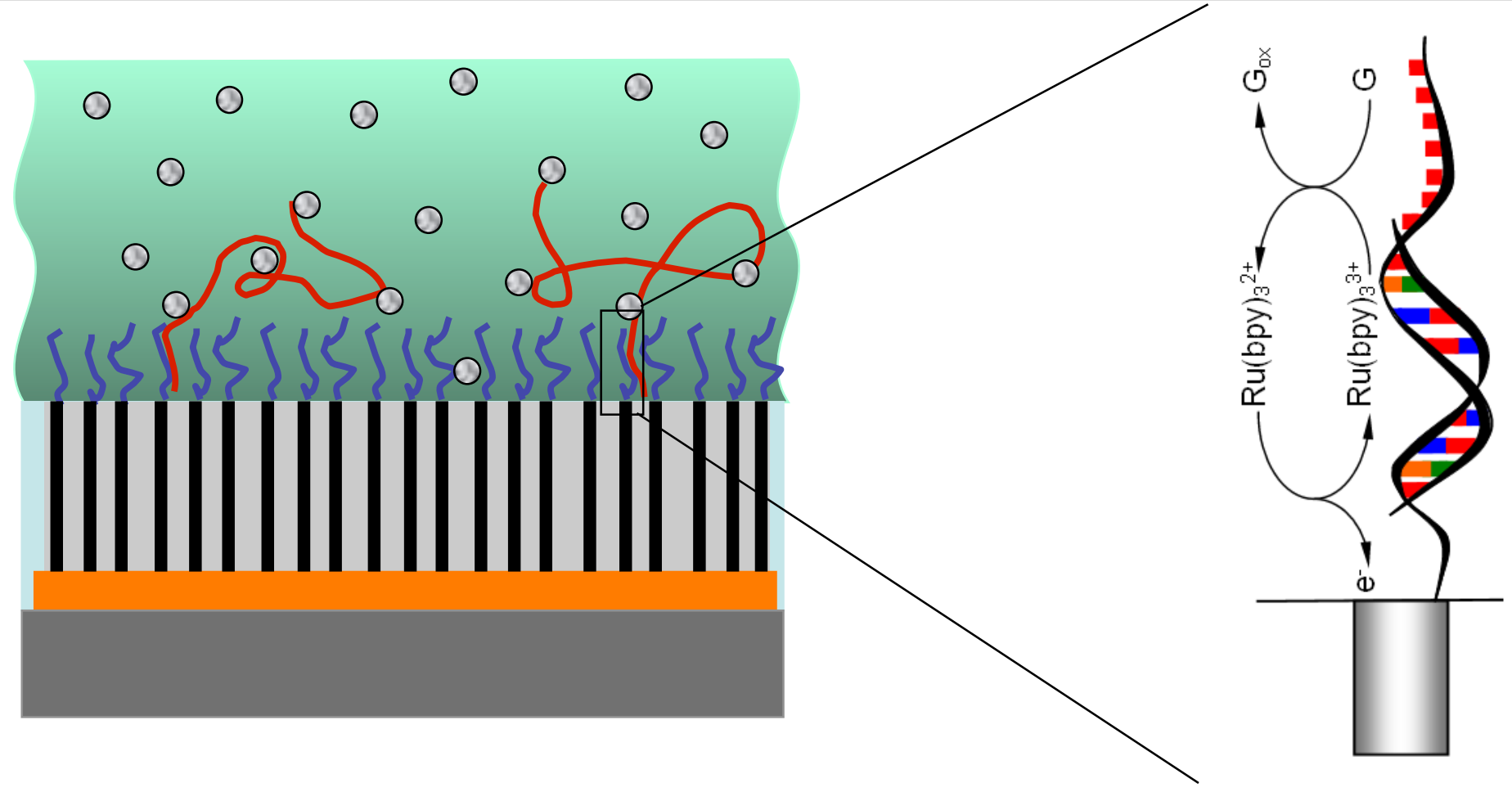

$\square$ CNF array electrode functionalized with DNA probe as an ultrasensitive sensor for detecting the hybridization of target DNA from the sample.

- Signal from redox bases (Guanine) in the excess DNA single strands

The signal can be amplified with metal ion mediator. 


\section{Electrochemical Detection of DMA Hybridization} By AC Voltammetry
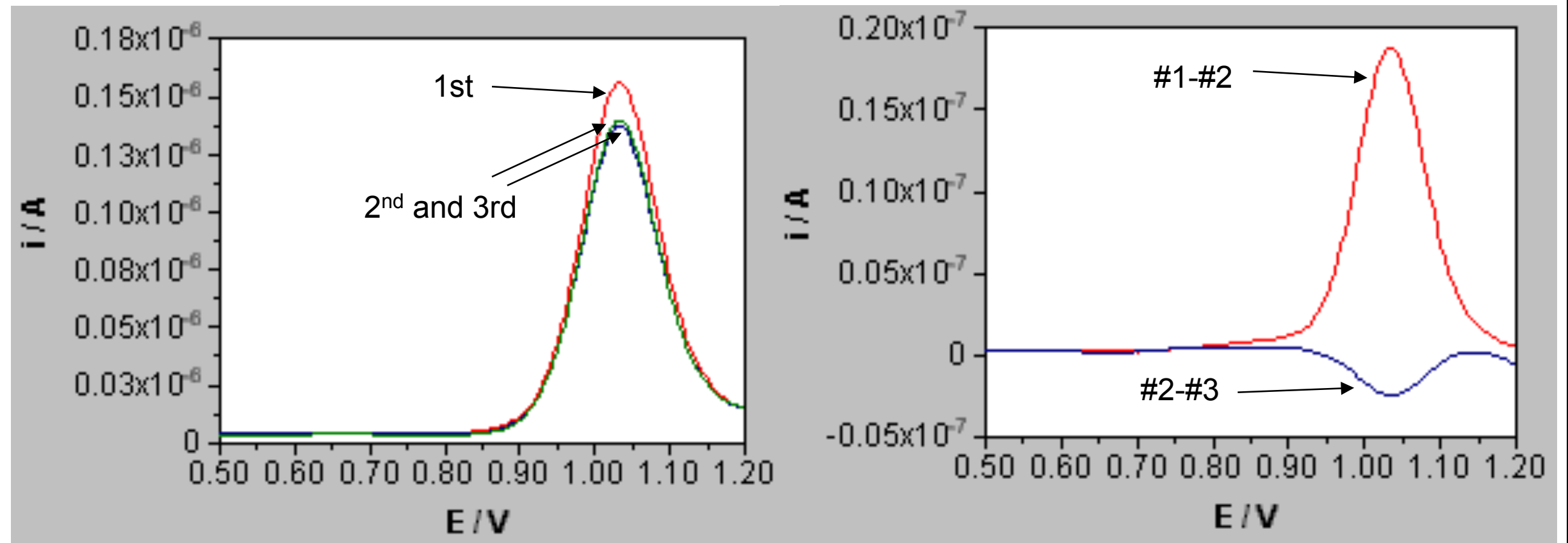

$1^{\text {st }}, 2^{\text {nd }}$, and $3^{\text {rd }}$ scan in AC voltammetry

$$
\begin{aligned}
& 1 \text { st }-2^{\text {nd }} \text { scan: mainly DNA signal } \\
& 2^{\text {nd }}-3^{\text {rd }} \text { scan: Background }
\end{aligned}
$$

Lower CNF Density $\Rightarrow$ Lower Detection Limit

J. Li, H.T. Ng, A. Cassell, W. Fan, H. Chen, J. Koehne, J. Han, M. Meyyappan,

NanoLetters, 2003, Vol. 3, p. 597. 


\section{Deep Brain Stimulation}

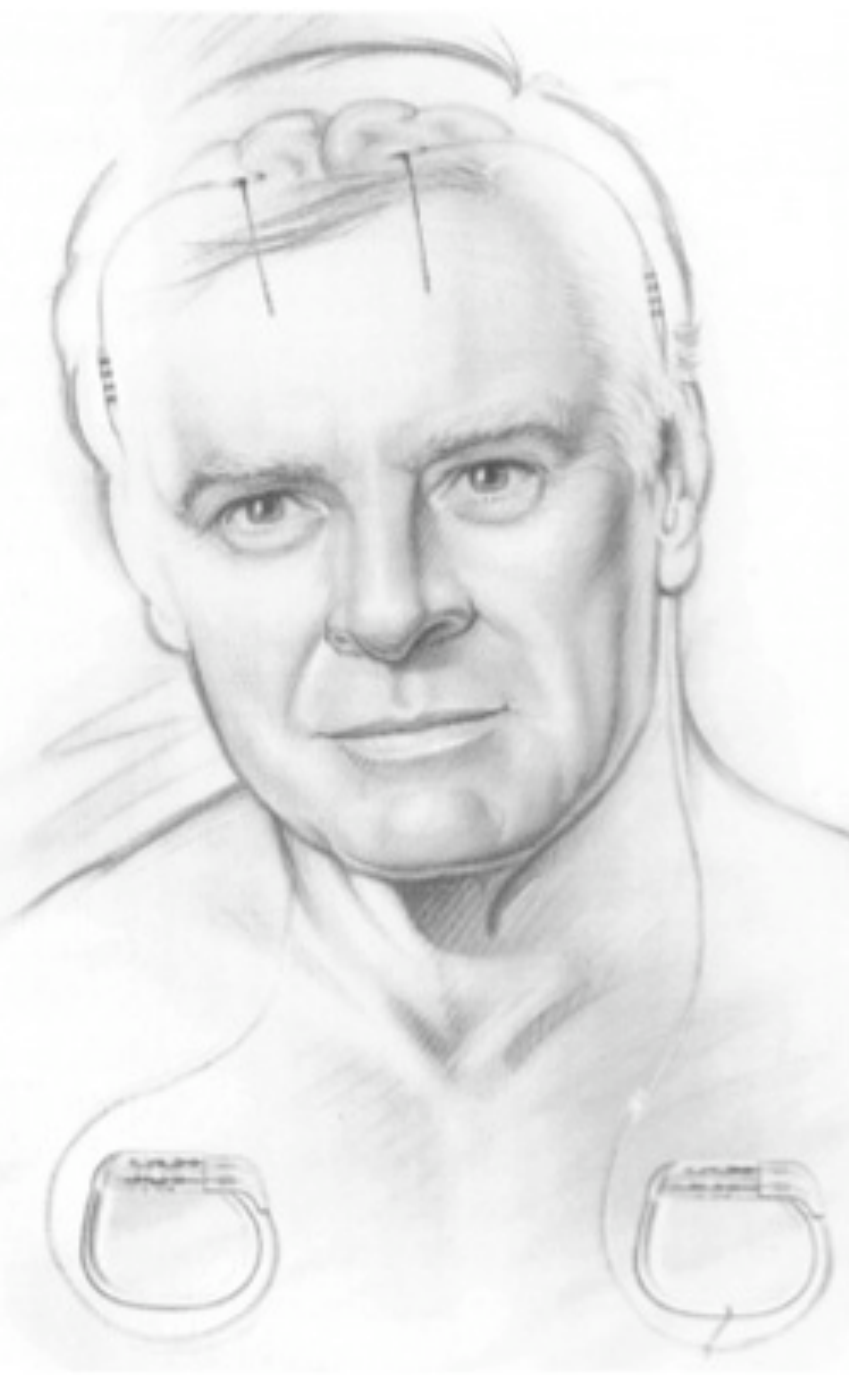

Medtronic

\section{Deep Brain Stimulation (DBS)}

Has been demonstrated to be an effective neurosurgical treatment for several pathologies including:

- Parkinson's disease $(30,000-40,000$ patients $)$

- chronic pain (1500-2000 patients)

- tremor (500-1000 patients)

- epilepsy (20-50 patients)

- depression (20-50 patients)

- Tourette syndrome (10-50 patients)

Expert Rev Med Devices 4:591-603, 2007

\section{How: Four Interrelated Hypotheses}

Paradox of similar effects to lesioning of target structure is explained by the following:

- Depolarization Blockage

- Synaptic Inhibition

- Synaptic Depression

- Stimulation Induced Modulation of Pathways 


PROBLEMS: Indiscriminate
Activation
- Stimulation indiscriminately affects all
tissue around the electrode (size: $1.27 \mathrm{~mm}$
diameter with four 1.5mm contacts)




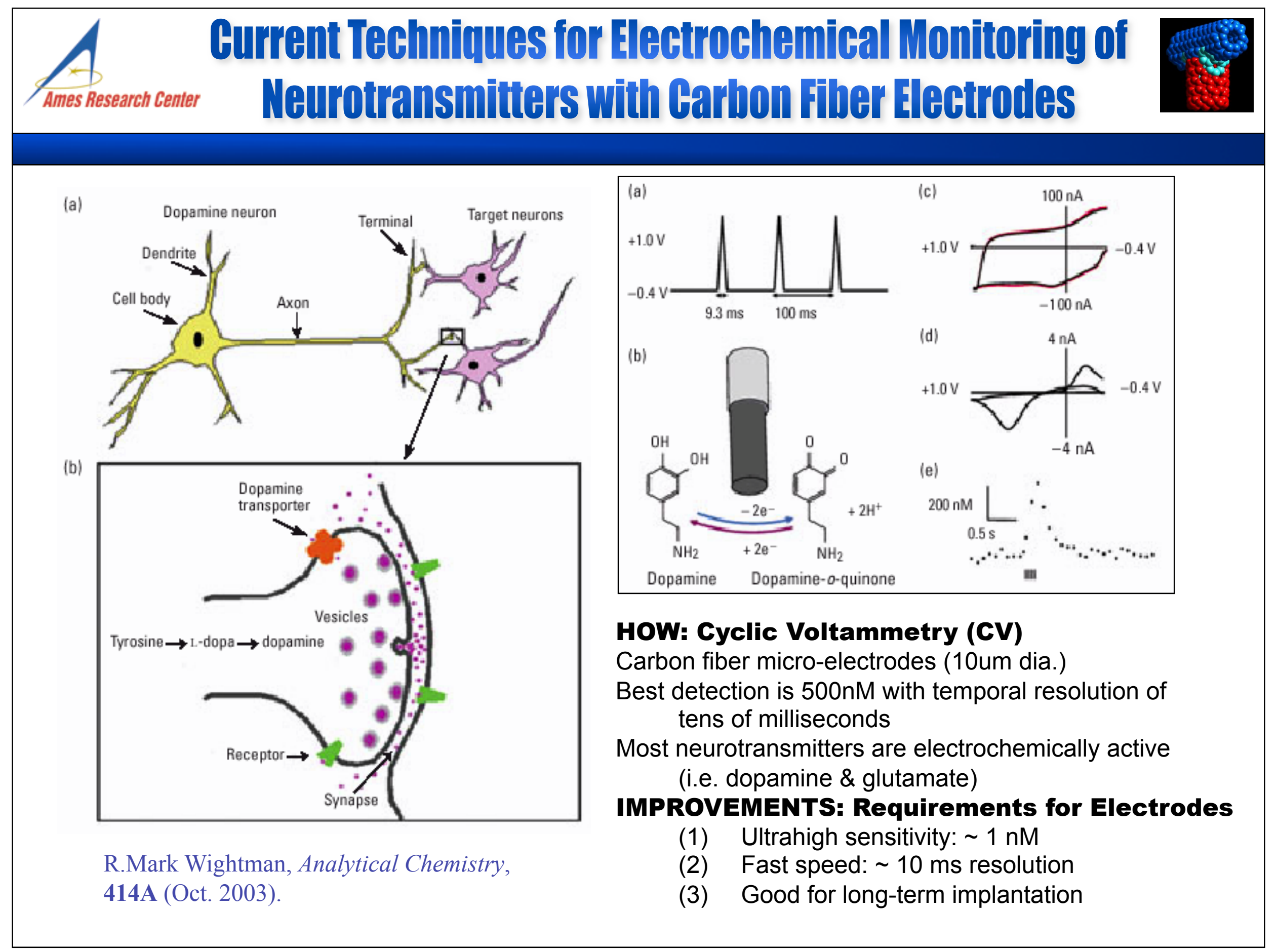




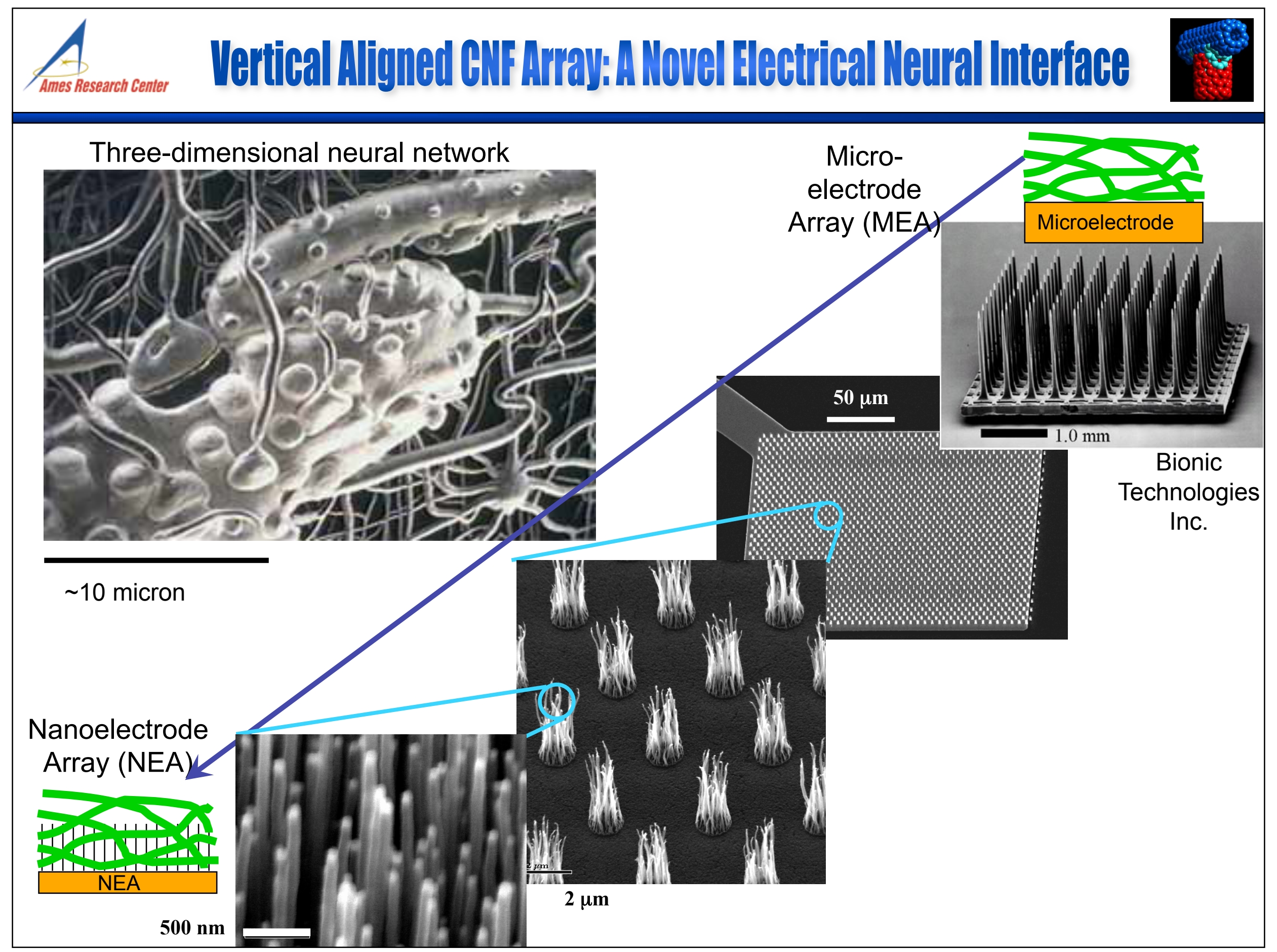




Goal: To Develop an Integrated Multiplex Ghip as an
Implantable Device for $\mathrm{BBS}$ and
Electrochemical Recording




\section{Polypyrrole Coated Vertically Aligned CMF Array for Neurostimulation}

Polypyrrole coating applied to increase the capacitance and decrease the impedance

As-grown CNF Array
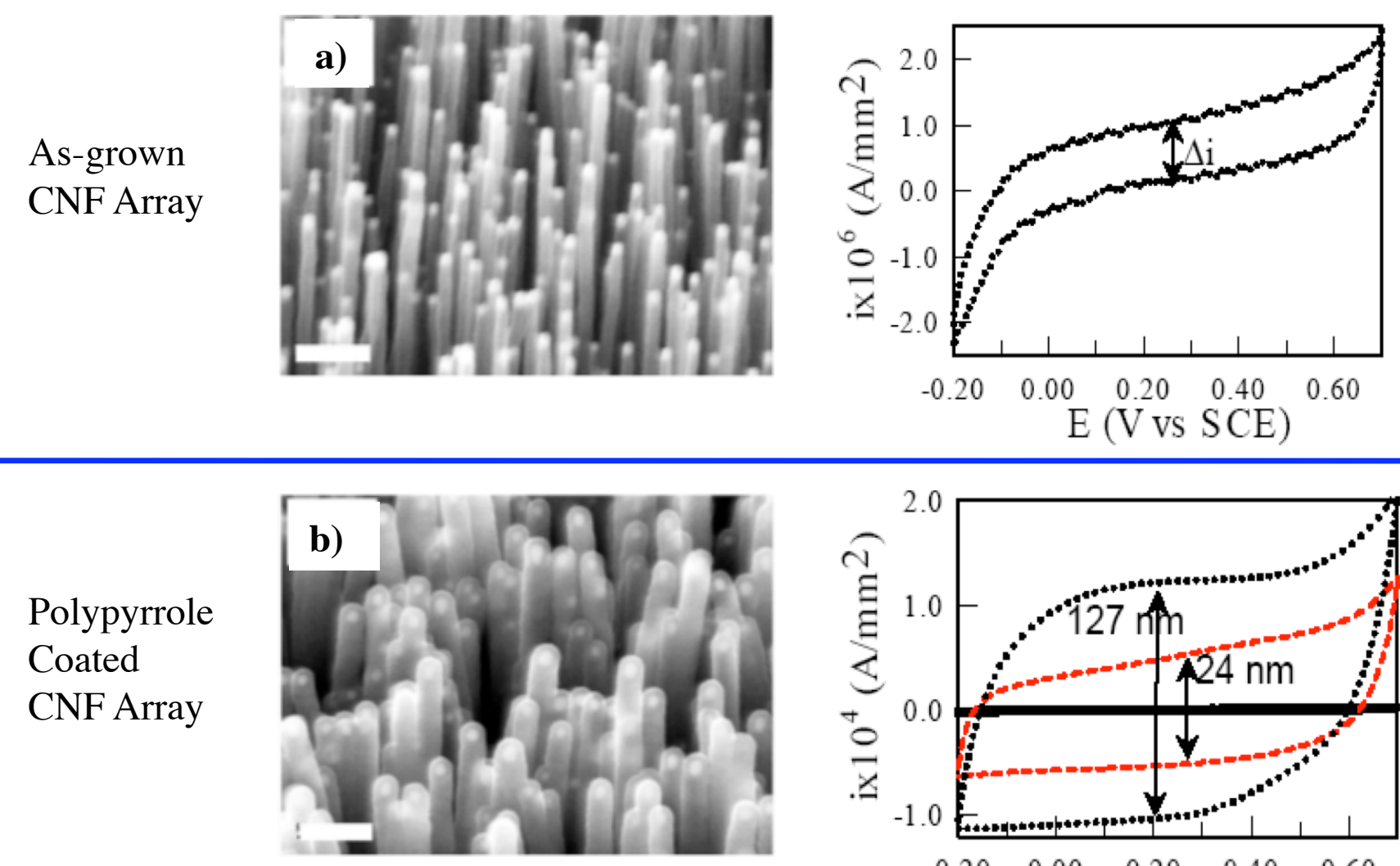

Nguyen-Vu, B. T. D., et al. Small 2006, 2, 89-94.

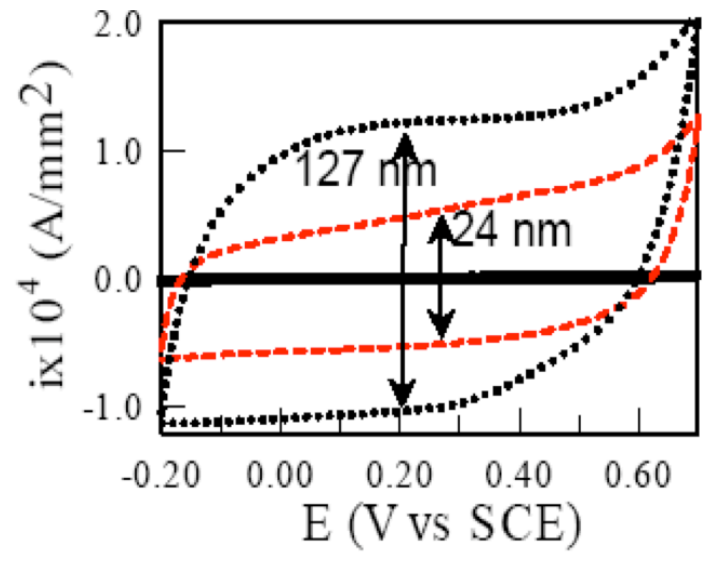

High Capacitance $\left(\mathrm{C}_{0}=\Delta \mathrm{i} / 2 \mathrm{v}\right)$ Noble metal $\sim 20 \mu \mathrm{F} / \mathrm{cm}^{2}$ As-grown CNF array: $0.4 \mathrm{mF} / \mathrm{cm}^{2}$ Ppy-coated CNF array: 40 to $100 \mathrm{mF} / \mathrm{cm}^{2}$
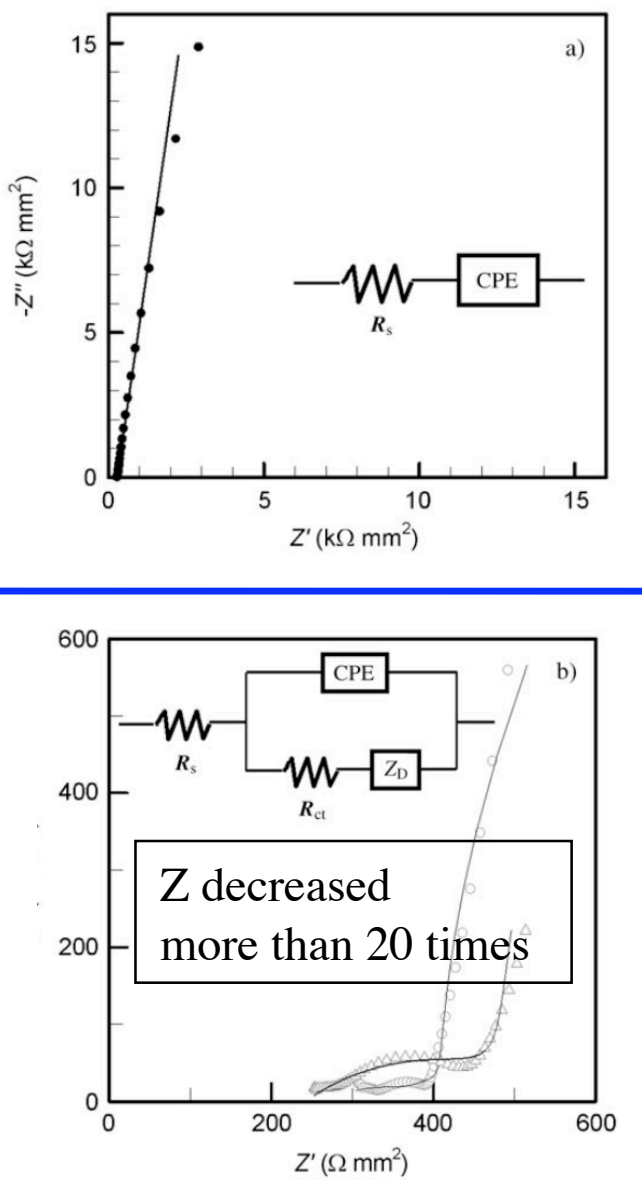

Low Impedance At $1 \mathrm{kHz}$, the impedance is negligible compared to the solution resistance 


\section{Biocompatahility of Polypyirole Coated Vertically Aligned GMF Array}

\section{PC12 Cell on Polypyrrole Coated CNFs}
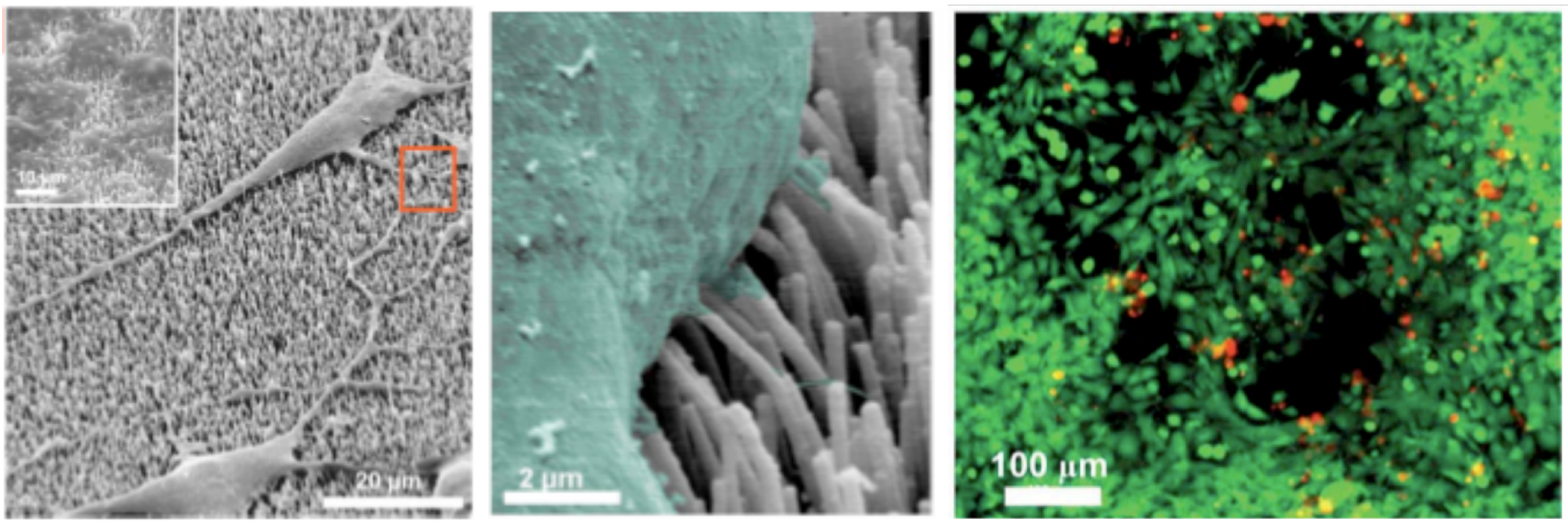

- Brush-like polypyrrole coated CNFs make intimate physical contact with PC12 cells

- PC12 cells observed to spread and differentiate on CNF array

- Polypyrrole coated CNFs support cell growth and proliferation 


\section{Stimulation of Rat Hippocampal Slice by Polypyirrole Coated Vertically Aligned CMF Array}

Experiment: Measure voltage for a given stimulation current

\section{Stimulation by:}

-W wire

Pt Microelectrode

- CNFs

$$
\bullet \text { PPy coated CNFs }
$$

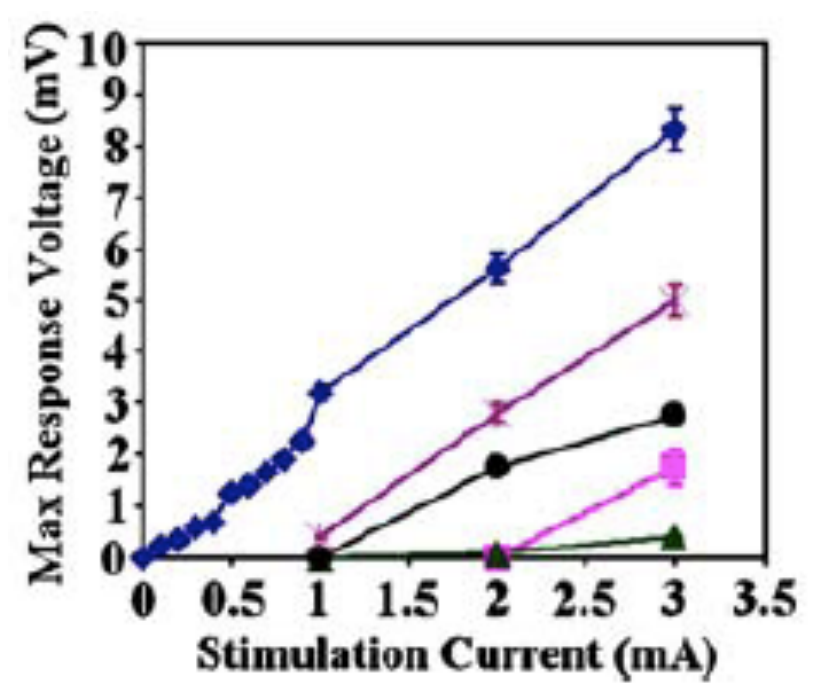

(a) Tungsten Electrode Stimulation

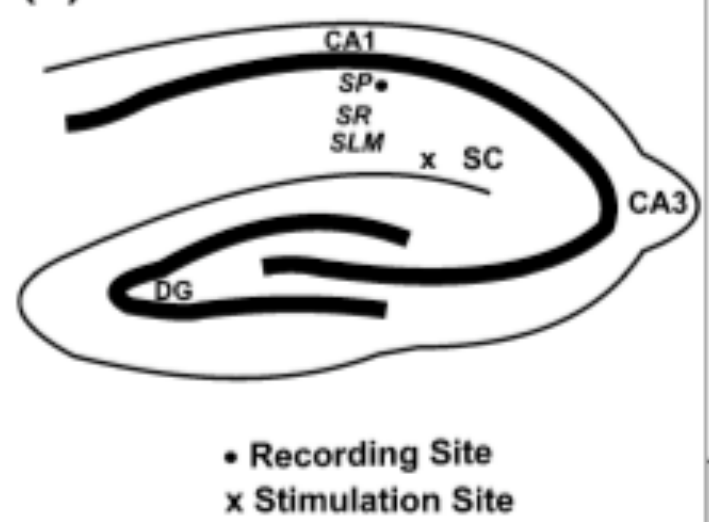

(b) Slice Placement on Electrode Array

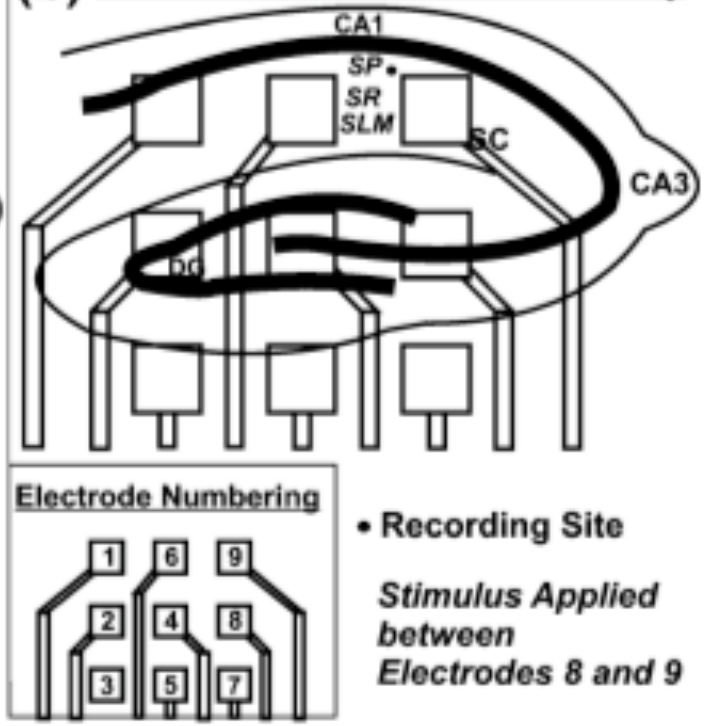

1) Only PPy coated CNFs were able to stimulate tissue under $1 \mathrm{~mA}$ stimulation current.

2) Only PPy coated CNFs did not induce the electrolysis of water (less than $1 \mathrm{~mA}$ and $1 \mathrm{~V}$ ) 


\section{Dopamine Detection by CHIF Array and}

\section{Mayo Clinic's Sterilizable WINCS Unit}
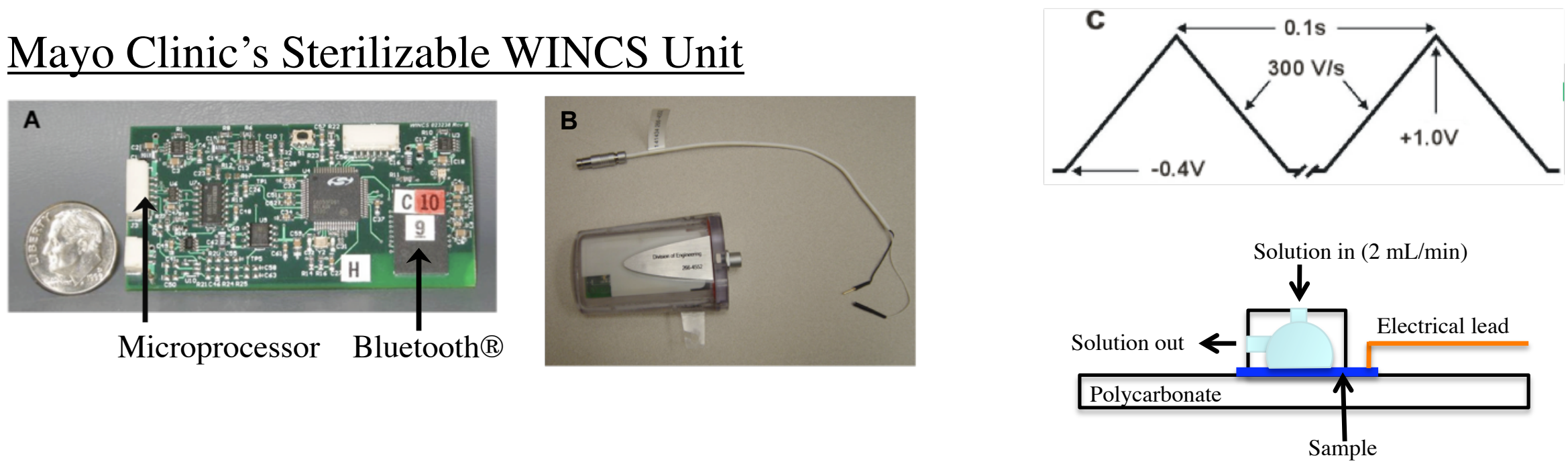

a

CNF BGS CV

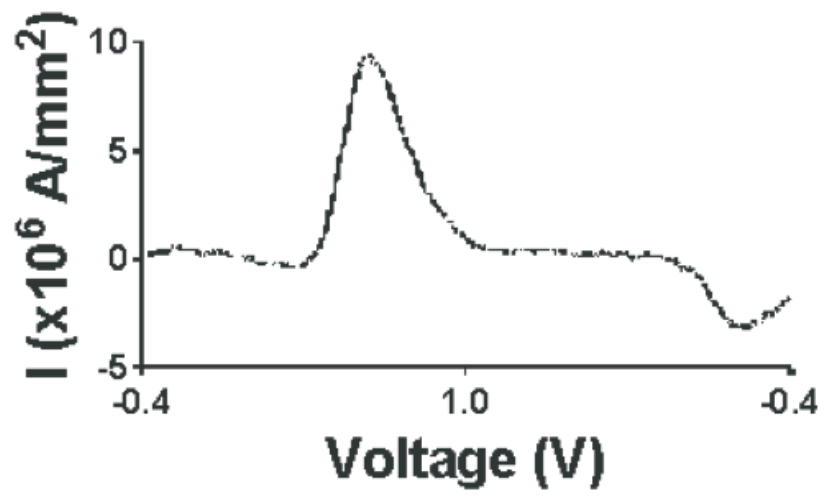

Koehne, J. E., et al. Analyst, 2011, 136, 1802-1805. b

CNF Calibration

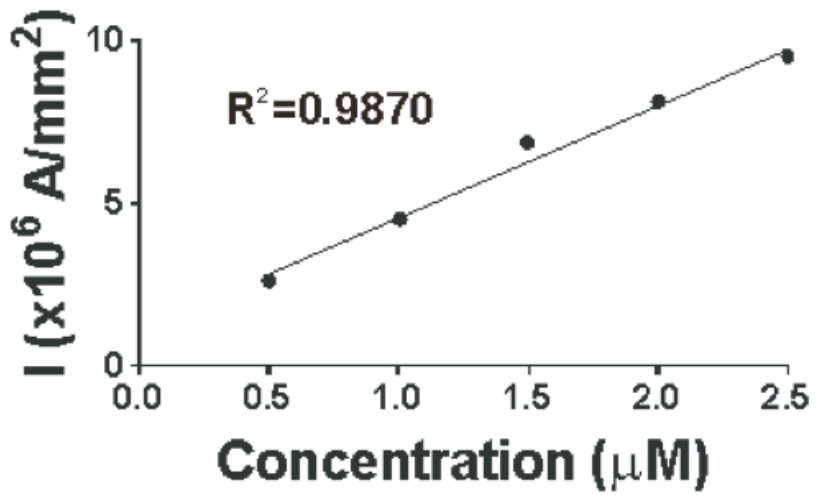

C CNF 2.5 $\mu \mathrm{M}$ Dopamine

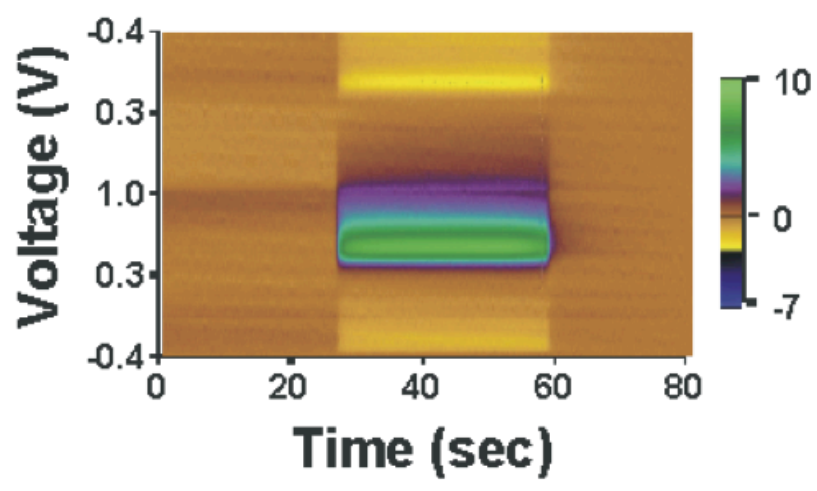




\section{Gas/Vapor Sensors in Biomedical Applications}

- Some diseases have specific markers which show up in excess concentration in the breath of sick people relative to normal people.

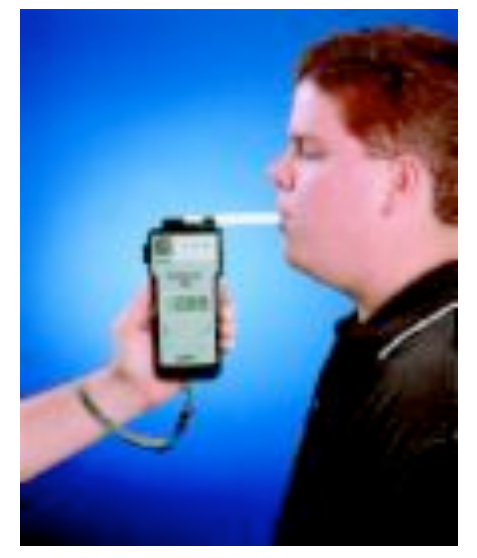

Examples: Acetone in diabetes patients $\mathrm{NO}$ in asthma patients

- In these cases, simple chemical sensors with pattern recognition can be valuable. 


\section{Why Nanomaterials//anosensors?}

- Compared to existing systems, potential exists to improve sensitivity limits, and certainly size and power needs

- Why? Nanomaterials have a large surface area. Example: SWCNTs have a surface area $\sim 1600 \mathrm{~m}^{2} / \mathrm{gm}$ which translates to the size of a football field for only $4 \mathrm{gm}$.

- Large surface area $\longrightarrow$ large adsorption rates for gases and vapors $\longrightarrow$ changes some measurable properties of the nanomaterial $\longrightarrow$ basis for sensing

- Dielectric

- Capacitance

- Conductance

- Deflection of a cantilever

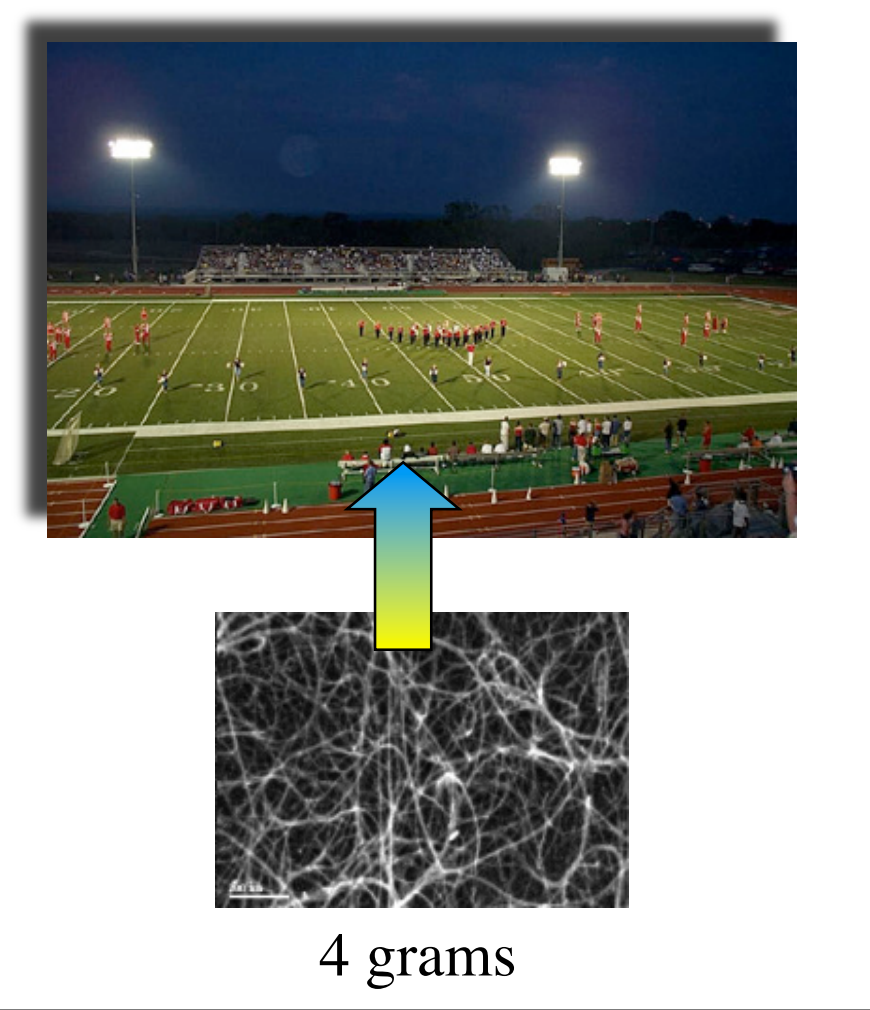




\section{SWCNT Chemiresistor}

- Easy production using simple microfabrication

- 2 Terminal I-V measurement

- Low energy barrier - Room temperature sensing

- Low power consumption: 50-100 $\mu \mathrm{W} /$ sensor
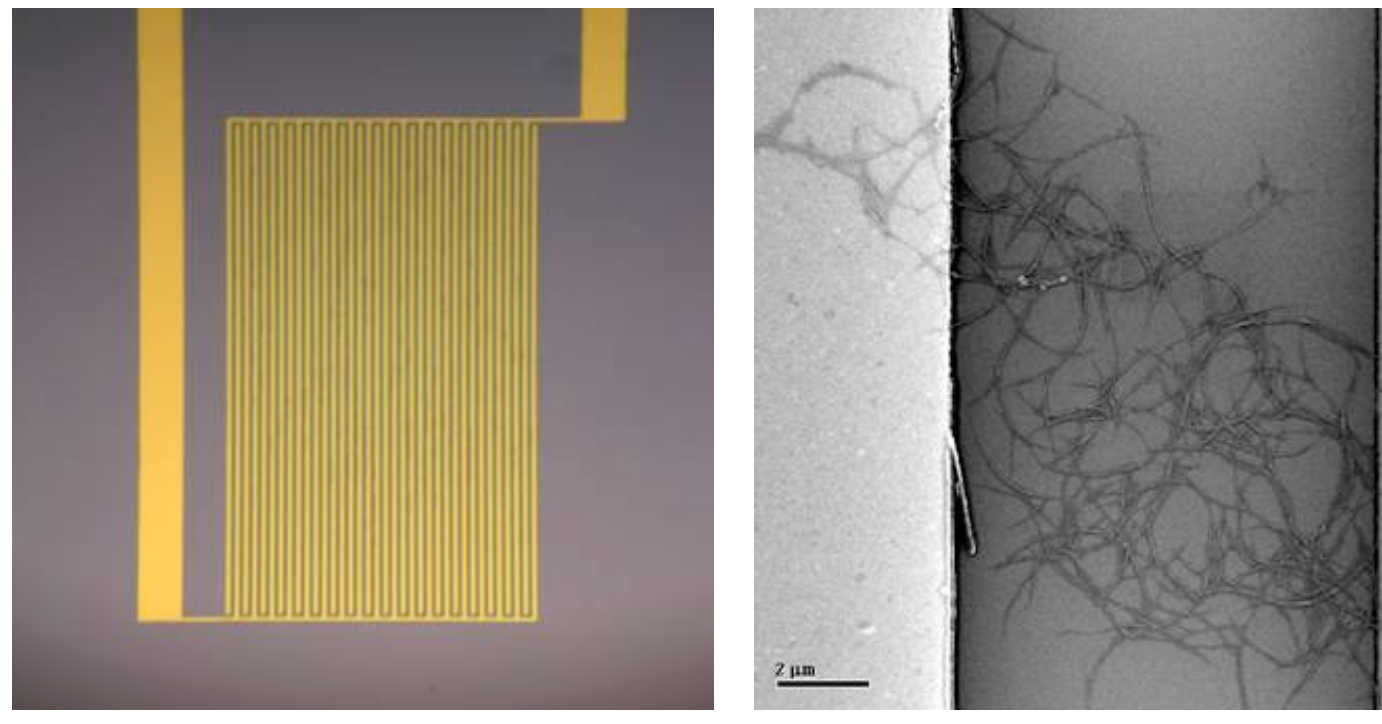

Processing Steps

1. Interdigited microscale electrode device fabrication

2. Disperse purified nanotubes in DMF (dimethyl formamide)

3. Solution casting of CNTs across the electrodes 


\section{SWCNT Sensor Testing}
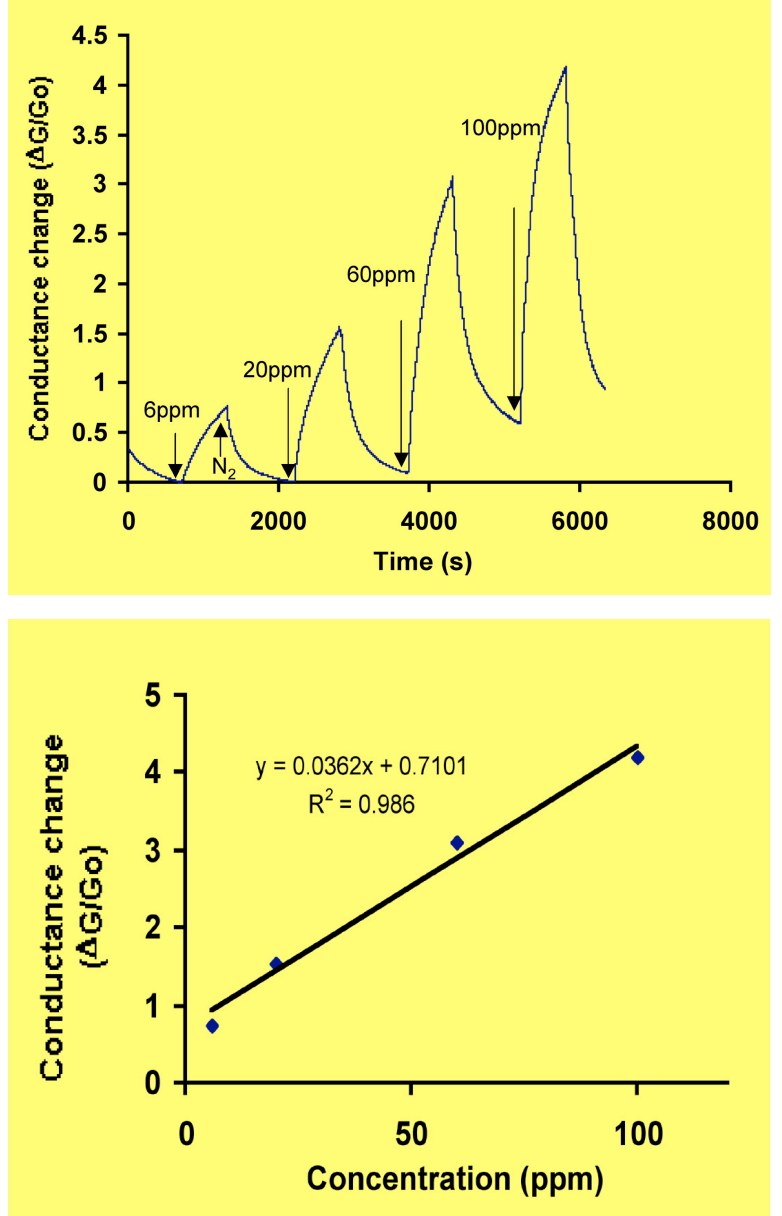

Detection limit for $\mathrm{NO}_{2}$ is $4 \mathrm{ppb}$.
- Test condition:

Flow rate: $400 \mathrm{ml} / \mathrm{min}$

Temperature: $23{ }^{\circ} \mathrm{C}$

Purge gas: $\mathrm{N}_{2}$ \& Carrier gas: Air

- Measure response to various concentrations, plot conductance change vs. concentration

Preliminary tests show a sensitivity of 10 ppm for acetone. Further studies are needed for interfering chemicals and pattern recognition. 


\section{Nanosensing Approach: Selectivity}

- Use a sensor array

- Variations among sensors

- physical differences

- coating

- doping

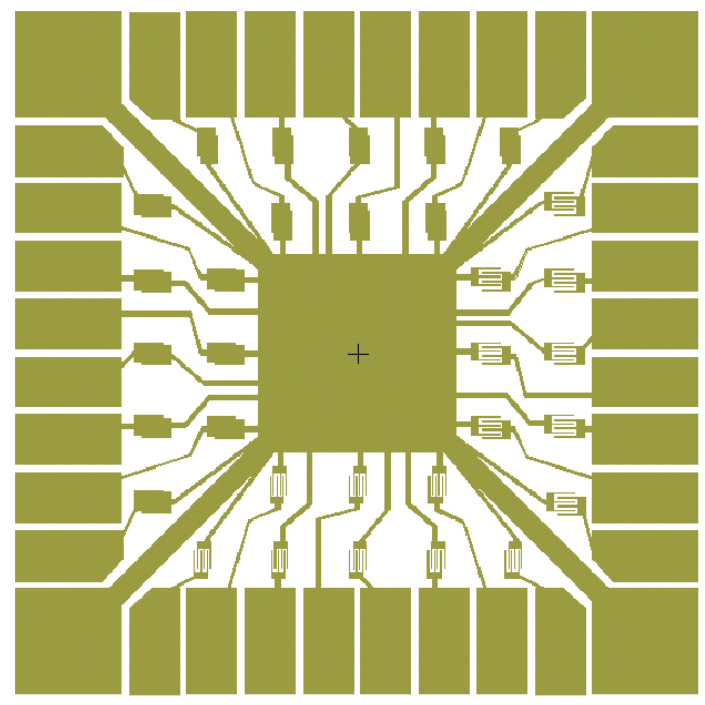

Operation:

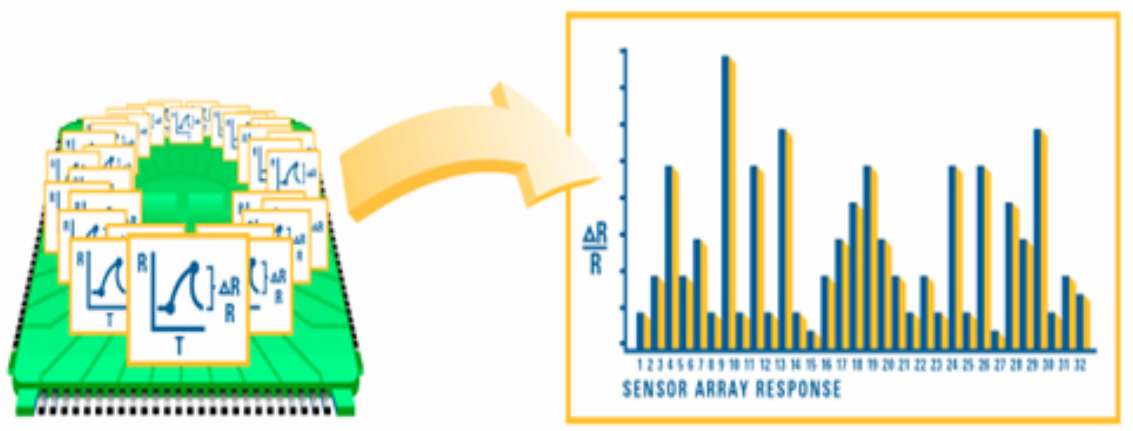

Using pattern matching algorithms, the data is converted into a unique response pattern

1. The relative change of current or resistance is correlated to the concentration of analyte.

2. Array device "learns" the response pattern in the training mode.

3. Unknowns are then classified in the identification mode.

4. Sensor can be "refreshed" using UV LED, heating or purging 


\section{CNTs in Ophthalmological Applications}

\section{Retinal Cell Transplantation}

- In the early stage of macular degeneration, retinal pigment epithelial (RPE) cells die, which leads to loss of photoreceptors. Solution?-replace the cells that are lost.

- RPE cells and iris pigment epithelial (IPE) cells can be harvested from the eye, grown in culture, then put back into the eye ("autologous transplantation"). 


\section{Problems with Retinal Cell Transplantation}

- Transplantation of suspensions of epithelial cells into the sub-retinal space fails to re-establish the proper architecture of the RPE layer. Instead of a sheet of uniformly oriented cells, you get a "jumble" of cells.

\section{Solution:}

- Establish the proper orientation of the epithelial cells prior to transplantation, by growing them in culture on a physical support: 


\section{Current Status, Problems and a Possible Solution}

- The Obvious Strategy: Natural Substrates for Retinal Transplantation

-Anterior Lens Capsule (basal lamina)

-Descemet's Membrane (posterior cornea)

Excellent growth of retinal epithelial cells, assembly of true "epithelial architecture."

Problem!: Membranes with attached epithelial cells cannot be easily implanted into the eye, because the membranes are flimsy and tend to "curl up." They lack the mechanical properties necessary for surgical handling.

Solution:

Carbon Nanotube Bucky Paper

A meshwork of carbon nanotubes formed into a paper-like structure

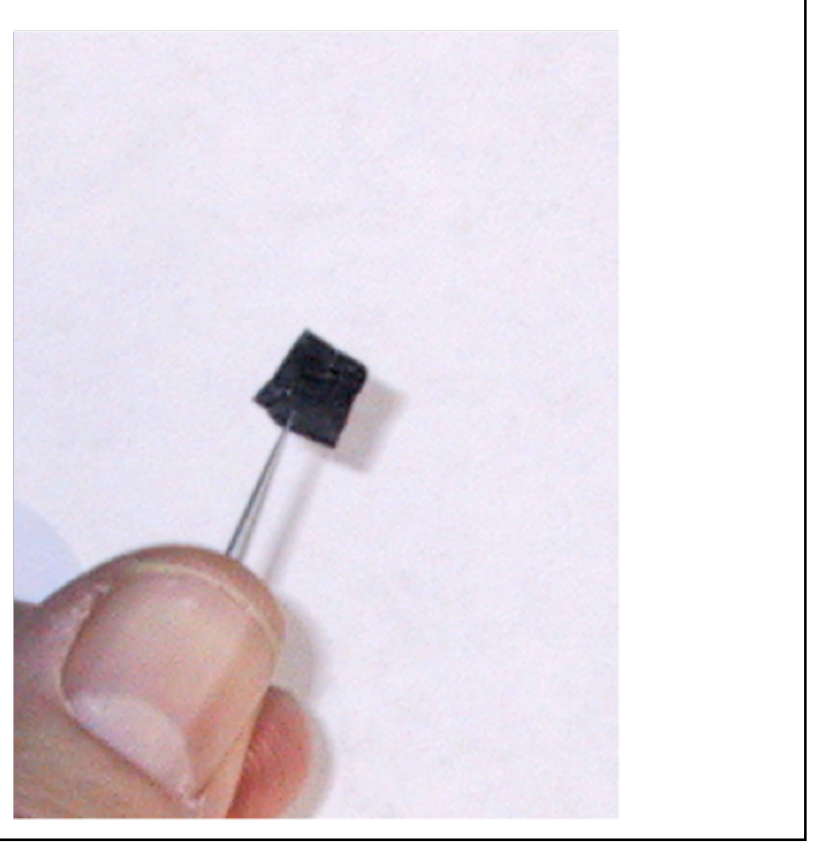




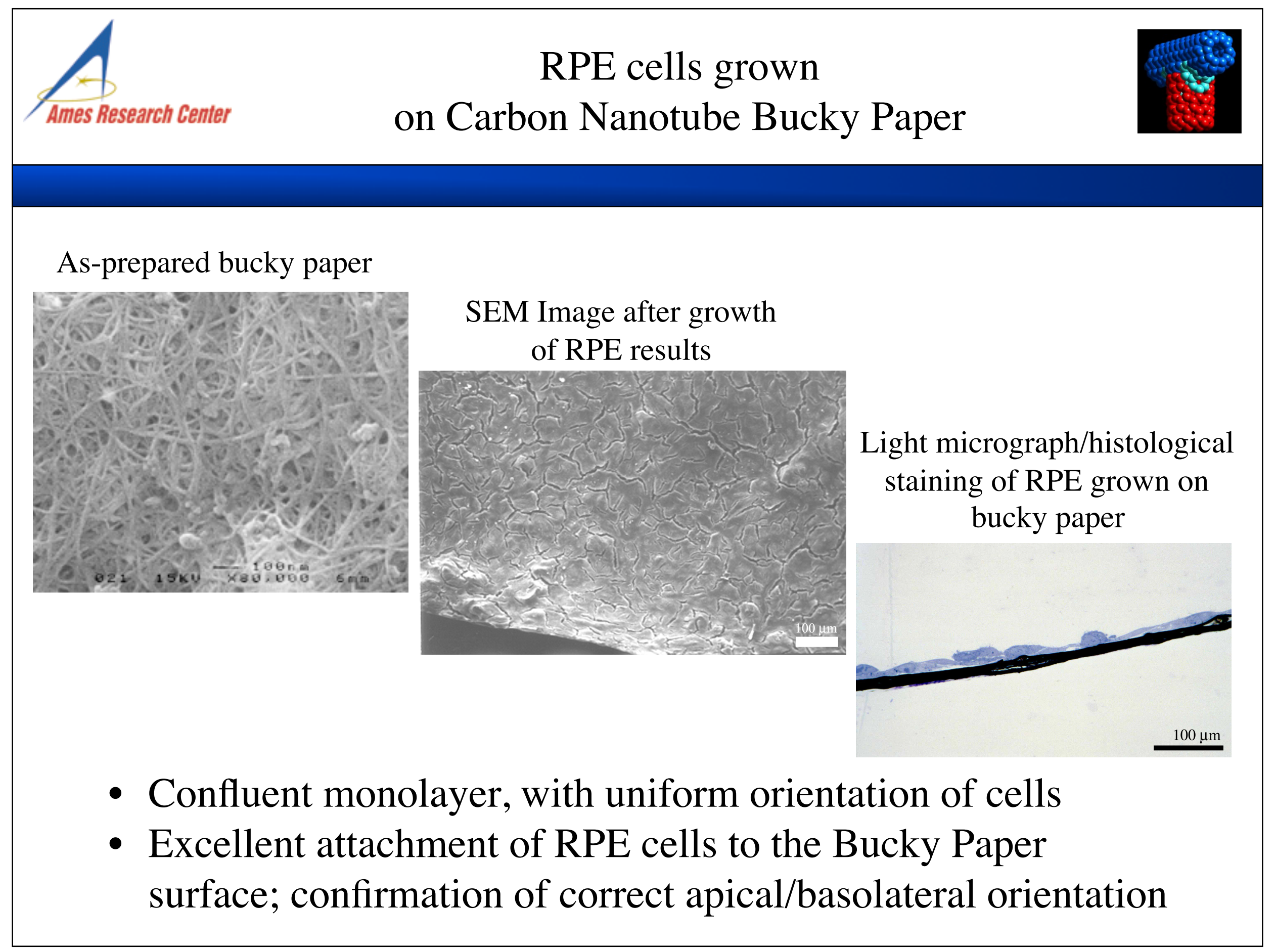


Implantation of Carbon Nanotube Bucky Paper into the Sub-Retinal Space of an Albino Rabbit

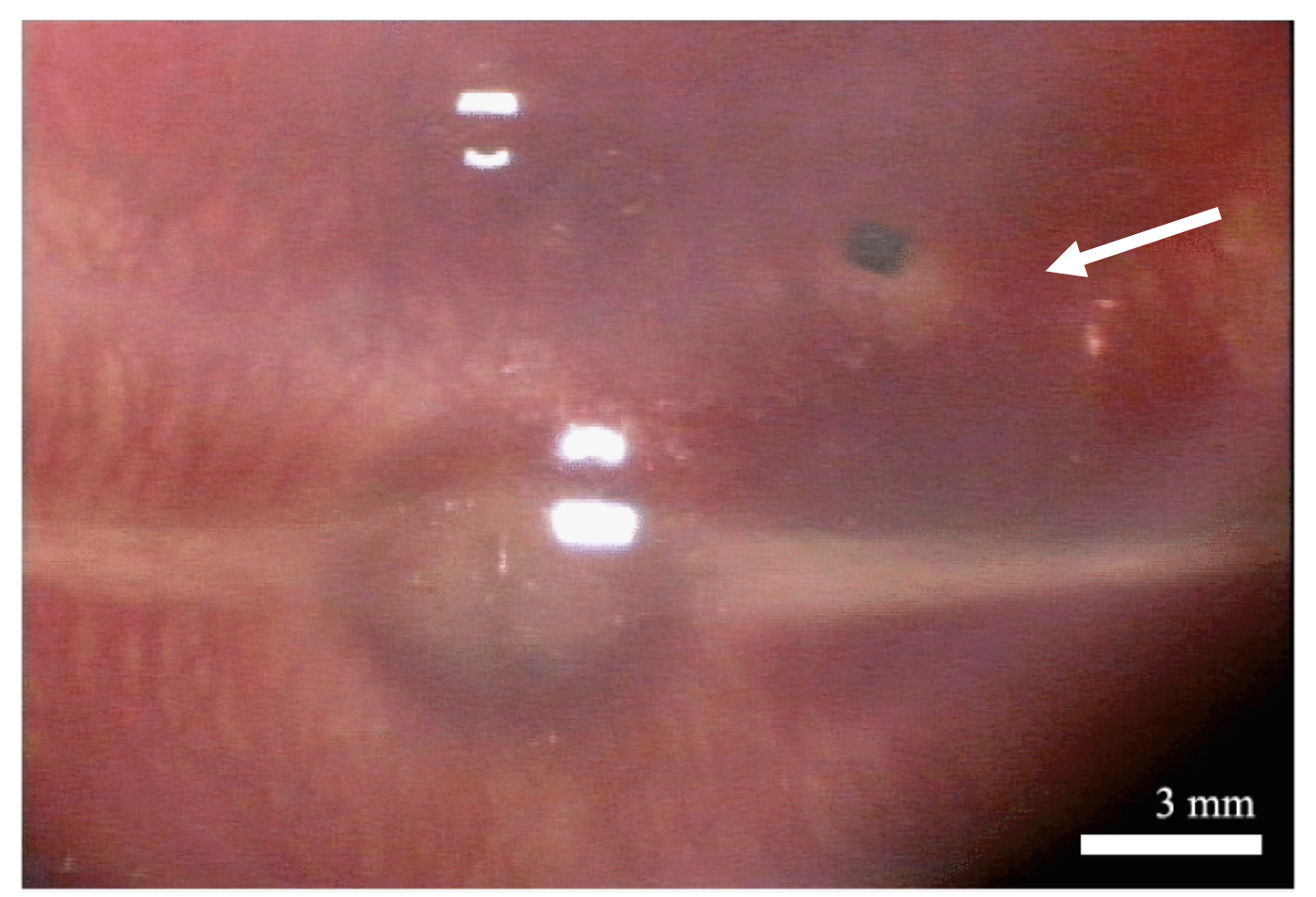

Result: Bucky paper is easily manipulated during surgery (does not tear and stays flat), and is immunologically well-tolerated by the eye. 


\section{Carbon Nanotube Biocompatibility}

Vision

Chip

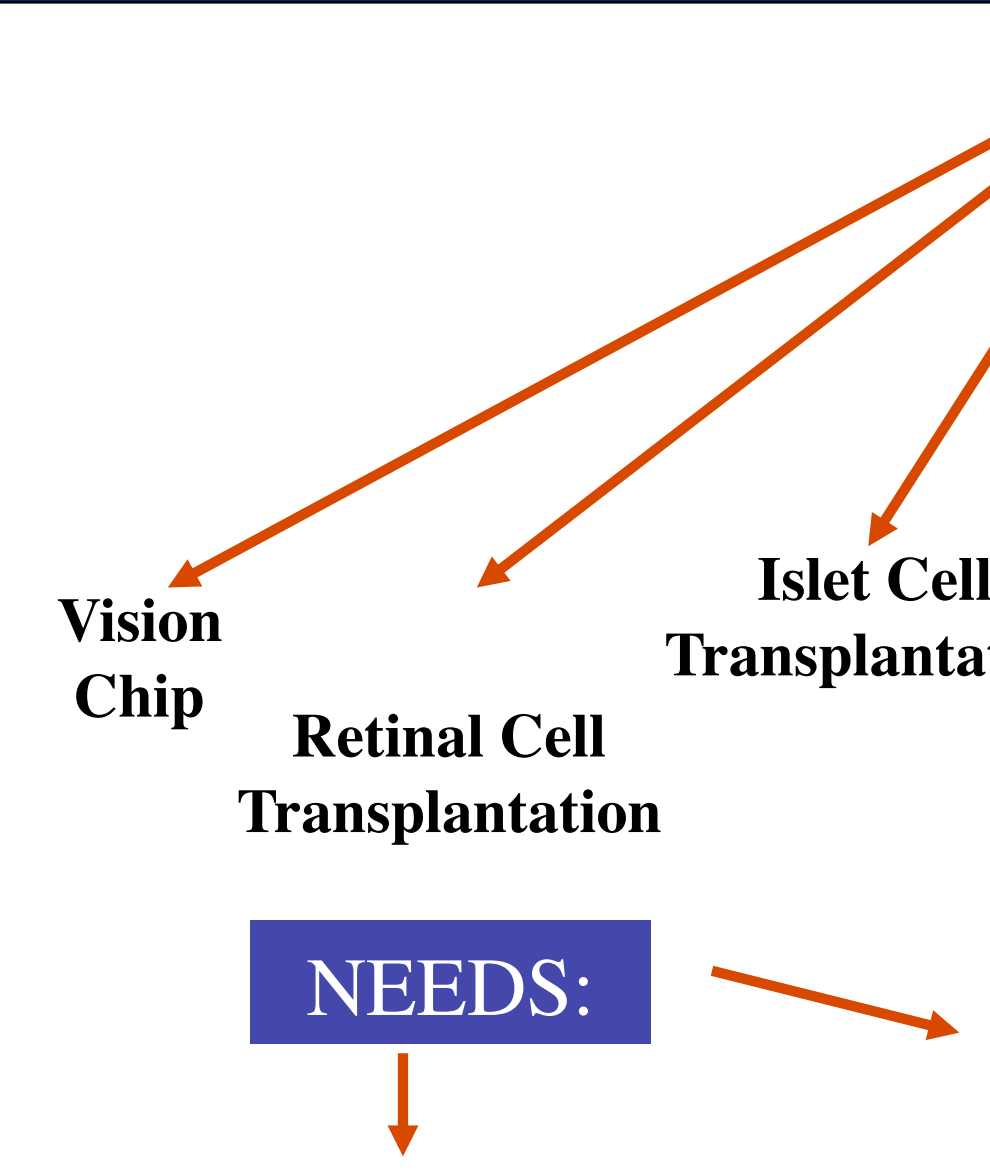

Implantable Physiological Sensors

-Remote sensing

-Early medical intervention

- Novel medical countermeasures

Cardiovascular physiology
Long Duration Space Flight -How to deliver medical therapy?

-Acute injury

Hemostatic Bucly Paper

Bucky Paper for Wound Healing

-Cancer Therapy

Adoptive Immunotherapy Delivered by Encapsulated Cells

Immune Shielded Delivery of Chemotherapy

-Therapy for diabetes

Transplantation of Islet Cells 
- Nanotechnology is an enabling technology that will impact almost all economic sectors: one of the most important and with great potential is the health/medical sector.

- Nanomaterials for drug delivery

- Early warning sensors

- Implantable devices

- Artificial parts with improved characteristics

- Carbon nanotubes and nanofibers show promise for use in sensor development, electrodes and other biomedical applications. 